\title{
Experimental Study on Notched Directional Blasting in Tensile Stress Field
}

\author{
Liyun Yang ${ }^{1, *}$, Huanzhen Xie ${ }^{1}$, Chen Huang ${ }^{1}$, Dongbin Zhang' and Yuh J. Chao ${ }^{2}$ \\ ${ }^{1}$ School of Mechanics and Civil Engineering, China University of Mining and Technology - Beijing, Beijing 100083, China \\ ${ }^{2}$ Department of Mechanical Engineering, University of South Carolina, Columbia, SC 29205, United States
}

Received 12 November 2019; Accepted 3 February 2020

\begin{abstract}
Notched blasting has been extensively applied as a traditional directional blasting method. At present, the measurement of notched blasting effect and rock fragmentation is mainly decided by the propagation behavior of blast-induced cracks. However, the influence of initial tensile stress field on such behavior is rarely considered in existing engineering blasting process, resulting in the non-remarkable directional fracture effect of tensile rock mass. To reveal the propagation behavior of the propagation behavior of blast-induced cracks in the initial tensile stress field, as well as the fracture failure mechanism, the stress distribution state and propagation mechanism of the blast-induced cracks near the notched hole under the combined action of initial tensile stress and blasting stress were determined on the basis of the theory of elastic and fracture mechanics. The combined dynamic-static loading device and digital laser caustic experimental system were used to conduct the planar model failure experiment under the joint action of the initial tensile and blasting stress. The influence laws of the initial tensile stress and notch angle on the propagation length and velocity of the blastinduced main cracks, as well as the stress intensity factor at the crack tip, were also investigated through the experiment. The results showed that, (1) In the initial tensile stress field, as circumferential tensile stress was generated at the blasthole wall by initial tensile stress, the blast-induced main crack could be more easily propagate in the direction perpendicular to the initial tensile stress. (2) When the angle between the notch and the initial tensile stress was $45^{\circ}$, the initial tensile stress enlarged the propagation length of the main crack, and the propagation mode transitioned from Mode I to I-II mixed mode. In the meantime, the main crack deflected perpendicular to the initial tensile stress. (3) When the notch was parallel to the initial tensile stress, the main crack demonstrated a linear propagation along the direction of initial tensile stress. The initial tensile stress promoted the generation of the secondary cracks in the two sides of the blasthole and shortened the propagation length of the main crack, thereby reducing the stress intensity factor of the main crack. Results can serve as a reference for directional blasting in the initial static tensile stress field.
\end{abstract}

Keywords: Tensile stress field, Notched blasting, Caustics, Blast-induced main cracks

\section{Introduction}

Given that notched blasting can improve the engineering blasting quality and efficiency effectively and mitigate its disturbing effects on buildings (structures) or rock masses around the blasthole, it has been extensively used in the directional demolition of buildings (structures) [1] and exploitation of mineral resources [2]. Notched blasting has also been applied to complicated engineering environments with the development of engineering practices. Directional notched blasting is typically applied in buildings (structures) or rock masses within the initial static stress field (tensile or compressive). For instance, in the exploitation process of deep mineral resources, the high ground stress is an important factor needing consideration in the roadway excavation process. Similarly, the effects of the static tensile stress in the midspan region caused by the excessively large span of the bridge floor should be considered in the directional blasting demolition of long-span bridges. The effect of initial static tensile stress should also be considered in forced roof caving through the directional blasting method. In the blasting construction at the initial static stress field, the initial static tensile stress changes the stress concentration state of media around the blasthole in the

*E-mail address: yangly@cumtb.edu.cn

ISSN: 1791-2377 C 2020 School of Science, HHU. All rights reserved.

doi:10.25103/jestr.131.14 initial blasting phase, thereby influencing the propagation behavior of blast-induced cracks and the blasting effect. Therefore, the notched blasting action mechanism under the initial stress field, especially under a tensile one, should be investigated.

In traditional notched blasting, the notched blasthole is excavated on the demolished building (structure) or rock, followed by charging and backfilling. During blasting, the notched blasthole will concentrate and direct the blast energy to the design rupture plane overlapped with the tangent plane, thereby causing high stress concentration at the notch tip, inhibiting the generation and propagation of cracks in the adverse direction, and reducing the damage of the two walls of the notched blasthole due to blasting stress [3]. However, many engineering practices suggest that the crushing effect of notched blasting in the initial static stress field greatly differ from that in the traditional notched blasting; thus, the traditional notched blasting mechanism cannot explain the propagation behavior of the notched blast-induced cracks under the initial static stress reasonably.

With the development of computer technology, finite and discrete element methods [4-6] have provided effective analytical means to enable scholars to study the action mechanism of directional notched blasting in the initial static stress field (e.g., numerical analog calculation through the boundary element calculation method for instant elasticdynamic problem) through repeated modeling. This 
approach can simulate the action mechanism of notched blasting on the blast medium and the stress distribution around the blasthole to a certain degree. However, the outcome still deviates from the actual blasting action. To increase the precision of the results, the element division should be refined. However, this step results in long calculation times, and some computers with poor configurations cannot satisfy the computation requirements. Therefore, large-scale workstations with high configurations should be utilized to execute rapid calculations, resulting in poor economic efficiency. In addition, notched blasting under the action of initial static stress involves more complicated conditions than traditional notched blasting. In consideration of the action of initial static stress, the dynamic relaxation method is usually used for processing. However, the initial stress state of the rock mass is difficult to explain. Given the existence of these problems and the long-term lack of theoretical and experimental guidance in related studies, the reliability of the study results is unsatisfactory and therefore cannot guide the relevant engineering practices accurately.

On this basis, to study the propagation behaviors of notched blast-induced cracks under initial tensile stress, this study combined theoretical analysis and model test method to establish a basis for engineering practice of notched blasting under complicated load conditions.

\section{State of the art}

Rock fracture control is the key to blasting, and notched blasting, which is a highly practical directional blasting method, has addressed this issue effectively. Domestic and foreign scholars have conducted several research and obtained valuable results. In 1978, Fourney et al. [7] implemented a series of fracture control model tests firstly and proved that a suitable blasthole shape could control the rock fracture direction effectively. To further verify the feasibility of directional fracture blasting, Fourney applied the notch treatment and discovered that the existence of the notch could suppress the crack generation around the blasthole effectively and aggravate crack propagation at the notch tip [8]. Kim et al. [9] used the water abrasive jet cutting method to control the rock mass blasting of the excavated tunnel. The results showed that this method could mitigate the disturbance in the surrounding rocks in the tunnel and realize an effective control of directional blasting. Stockwell et al. [10] proved that notched blasting could effectively control energy transfer and reduce the rock disturbance by studying the crack propagation behavior in an open-pit coal mine exploitation process with notched blasting control. Moreover, this approach ensured the crushing degree of the target region and improved the mining efficiency. Liu et al. [11] used the caustic experimental system to analyze the blasting conditions of the round hole, square hole, and notched blasting specimens comparatively. They observed the propagation behavior of the blast-induced cracks and found that such cracks on the notched specimen did not experience deflection, thereby providing a theoretical basis for the shape of the directional fracture blasthole. Yang et al. [12] investigated the influence of notched blasting on the initial crack formation stage through a numerical simulation method and verified that notched blasting could control energy transmission and avoid an excessively large failure area of the rock mass through experiments effectively. However, the aforementioned studies only involved the propagation behavior of blast-induced cracks under the action of blasting stress, and are thus not applicable to blasting operations under the action of the initial static stress field. Therefore, the above study conclusions is limited to engineering applications.

To meet the blasting operation under complicated engineering conditions, scientific researchers have performed in-depth analyses. The findings revealed that the existence of the initial static stress field exert a great impact on the blasting effect. Dammyr et al. [13] explored the feasibility of hole drilling blasting method for deep sea tunneling. They discovered that the deep water pressure exerts great adverse effects on the tunneling process, as well as on the support of the tunnel wall. Yang et al. [14] studied the blast-induced crack propagation behavior of slotted charge blasting under initial static compressive stress using a dynamic caustic experiment and reported that the stress distribution around the blasthole and the blast-induced gas influences the entire propagation process. With respect to mining a region with high rock blasting risk, Konicek et al. [15] expounded the application of pressure blasting to rock masses and stated that the high ground stress had a certain influence on the blasting effect. Drover et al. [16] used the roadway pressure relief blasting technique to excavate a deep tunnel, introduced the interactive relationship between the blasting stress and overlying rock stress in the tunneling process and proposed that the optimal pressure relief charge consisted of initiating explosive at the initiation port, as well as completely sealed and coupled initiating explosive. Xie et al. [17] numerically simulated the cut blasting in deep tunnel using the LS-DYNA software to investigate the evolution mechanism of rock damage during cut blasting under the high ground stress of deep tunnels. The results indicate that ground stress exhibits a certain resistance against the radial pressure of the tunnel, as well as ductility to withstand the damage around the notch. Reddy et al. [18] studied the stress distribution laws under the different blasting exploitation phases of the roadway floor and revealed that ground stress exert a remarkable influence on roadway excavation.

The above studies have explored the blasting effect of the initial static compressive stress under all kinds of traditional blasting methods, as well as the corresponding effect on rock damage. However, the underlying mechanism of directional blasting (notched blasting) under the initial static tensile stress remains unexplored. Theoretical studies on notched blasting under tensile stress are lacking, and only few studies involved the propagation behavior of notched blast-induced cracks under the initial static tensile stress. Initial static tensile stress fields are prominent in different engineering practice (e.g., large area hanging roof above goaf in coal mining). The rock mass in the goaf is under tensile stress state, so large-area collapse will probably occur due to the low tensile strength of the rocks. To eliminate the potential dangers, blasting method is utilized to loosen hard rocks. The forced roof caving technique based on directional rupture control blasting is proposed in engineering production to reduce the number of blastholes and blasting workload, improve the production efficiency, and lower the construction cost $[19,20]$. Under specific circumstances, excavation and unloading result in stress redistribution, which generates tensile stress in the rock mass or civil architecture and achieves the directional blasting effect through notched blasting. Therefore, studying the notched blasting under the initial static tensile stress field possesses a great engineering significance. 
Therefore, to address the deficiencies of existing studies, theoretical analysis of notched blasting and propagation behavior of blast-induced cracks in initial static tensile stress were investigated in this work systematically. The remainder of this work is organized as follows. Section 3 presents the experimental design and system. Section 4 discusses the analysis of the notched blasting failure mechanism, description of the specimen failure modes, and analysis of the propagation behavior of the blast-induced main cracks and the dynamic stress intensity factor. Lastly, Section 5 summarizes the findings and provides the conclusions.

\section{Methodology}

\subsection{Experimental design}

Given the difficulty in collecting rock specimens and the impossibility of achieving projection in the caustic experiment, polymethyl methacrylate (PMMA) plate, which possesses the same brittle failure property as rock, was used to replace the rock material as the experimental model [21, 22]. The dynamic characteristic parameters of PMMA are listed in Table. 1.

The PMMA specimens with dimensions of $320 \mathrm{~mm} \times 300$ $\mathrm{mm} \times 5 \mathrm{~mm}$ were used in the notched blasting test, and the blasthole with a diameter of $6 \mathrm{~mm}$ was placed in the center of the plate. The opening angle and depth of the notch were $60^{\circ}$ and $2 \mathrm{~mm}$, respectively. Each group of specimens was added with $100 \mathrm{mg}$ of lead azide explosive through coupled charging and applied with static tensile stresses of $0 \mathrm{MPa}$ and $5 \mathrm{MPa}$. The two experiment groups were divided according to the included angle $\beta$ between the notch and the initial tensile stress ( $\mathrm{S} 1$ and $\mathrm{S} 2$ when $\beta=45^{\circ}$ and $0^{\circ}$, respectively). The grouping results are provided in Table. 2 .

Table 1. Dynamic characteristics of PMMA

\begin{tabular}{c|c|c|c|c|c}
\hline Poisson's ratio & $\begin{array}{c}\text { Elasticity modulus } \\
(\mathbf{G P a})\end{array}$ & $\begin{array}{c}\text { Transverse wave } \\
\text { velocity }(\mathbf{m} / \mathbf{s})\end{array}$ & $\begin{array}{c}\text { Longitudinal wave } \\
\text { velocity }(\mathbf{m} / \mathbf{s})\end{array}$ & $\begin{array}{c}\text { Optical constant } \\
\left(\mathrm{m}^{2} / \mathbf{N}\right)\end{array}$ & $\begin{array}{c}\text { Density } \\
\left(\mathbf{k g} / \mathrm{m}^{3}\right)\end{array}$ \\
\hline 0.31 & 6.1 & 1260 & 2320 & $1.08 \times 10^{-10}$ & 1230 \\
\hline
\end{tabular}

Table 2. Notched blasting groups

\begin{tabular}{c|c|c|c}
\hline $\begin{array}{c}\text { Group } \\
\text { number }\end{array}$ & $\begin{array}{c}\text { Specimen } \\
\text { number }\end{array}$ & $\begin{array}{c}\text { Initial tensile } \\
\text { stress (MPa) }\end{array}$ & $\begin{array}{c}\text { Included } \\
\left.\text { angle } \mathbf{(}^{\mathbf{}}\right)\end{array}$ \\
\hline \multirow{2}{*}{ S1 } & S1-1 & 0 & 45 \\
& S1-2 & 5 & 45 \\
S2 & S2-1 & 0 & 0 \\
& S2-2 & 5 & 0 \\
\hline
\end{tabular}

\subsection{Experimental system}

The caustics method is a method developed from experimental mechanics and used to measure the singular parameters of the materials. The mapping region in the principle of physical optics is used to transform the highstress and high-strain concentration region generated in the material into a clear optical image. A new type of digital laser dynamic caustic experimental system was adopted in this study (Fig. 1). The equipment used in the experiment include laser, beam expander, field lens, and high-speed camera; the laser and the high-speed camera are the core equipment. In the experimental process, the stable light source was emitted from the laser and then diffused into field lens 1 through the field lens. The light became a group of parallel lights, which entered the specimen after passing through field lens 1, and then parallel lights entered field lens 2 and converged into the high-speed camera. The highspeed camera recorded the entire change process of the caustic speckles and completed the digital acquisition work.

According to the caustic spots of the crack tip shot by the high-speed camera, the dynamic stress intensity factor can be expressed as follows:

$$
\begin{aligned}
& K_{\mathrm{I}}=\frac{2 \sqrt{2 \pi}}{3 g^{5 / 2} z_{0} c d_{\mathrm{eff}} \lambda_{m}^{3 / 2}} D_{\max }^{5 / 2} \\
& K_{\mathrm{II}}=\mu K_{\mathrm{I}}
\end{aligned}
$$

where $K_{\mathrm{I}}$ and $K_{\mathrm{II}}$ are the dynamic stress intensity factors of Modes I and II, respectively; $D_{\max }$ is the maximum diameter of the caustic speckle along the crack direction; $g$ is the numerical factor; $\mu$ is the proportionality coefficient of the stress intensity factor; $z_{0}$ is the distance from the reference plane to the specimen; $c$ is optical constant of the specimen material; $d_{\text {eff }}$ is the specimen thickness.

The dynamic-static combined loading system is shown in Fig. 2. The MTS testing machine provided the static tensile load for the PMMA specimen. One end of the PMMA specimen was connected to a fixed end, whereas the other was stretched upward with the testing machine. The computer port of the testing machine recorded the load value and deformation of the PMMA specimen during the entire loading process. The energy-gathering cartridge provided the dynamic blasting load for the PMMA specimen. The blasthole in the center of the specimen was filled with lead azide explosive, blocked and fixed using a fixture. One end of the detonating cord for the explosive was placed in the blasthole, whereas the other was connected to a high-voltage pulse initiator. The detonation of the explosive was completed using the electric spark generated by this pulse.

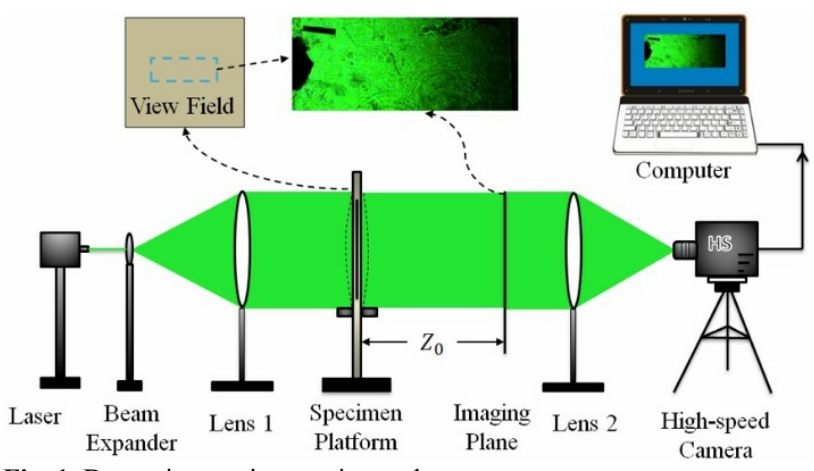

Fig. 1. Dynamic caustic experimental system

\section{Experimental results and analysis}

\subsection{Action mechanism of notched blasting under the} tensile stress field

During the detonation, the blasthole wall bore extremely high detonation shock wave, and the initial static stress field was negligible. The mechanical model of the formation phase of the blast-induced main crack is shown in Fig. 3. The V-shaped notch generated the dynamic effect of the 
blasting stress wave and the quasi-static effect of the blastinduced gas under the action of blasting stress. According to the rock crushing principle, rock is a kind of multi-crack or microcrack medium. In the blasting process, the blasting shock wave was generated around the blasthole, which in turn generated a crushing zone, as well as a pressure pulse, around the hole wall. Under the action of the pressure pulse, the stress wave experienced diffraction and reflection in the notch, consequently generating a strong dynamic stressstrain field at the notch tip. Moreover, the near-end compressive stress was generated near the tip and became a zone of the tangential stress and low tensile stress. This zone is the crack promotion inhibition zone, or simply inhibition zone. In conclusion, the propagation of microcracks in the region near the notch was obstructed due to the effect of the blasting stress wave. However, the stress in the direction of the notch tip was concentrated, and thus caused a prior crack propagation at the tip where the main crack was generated.

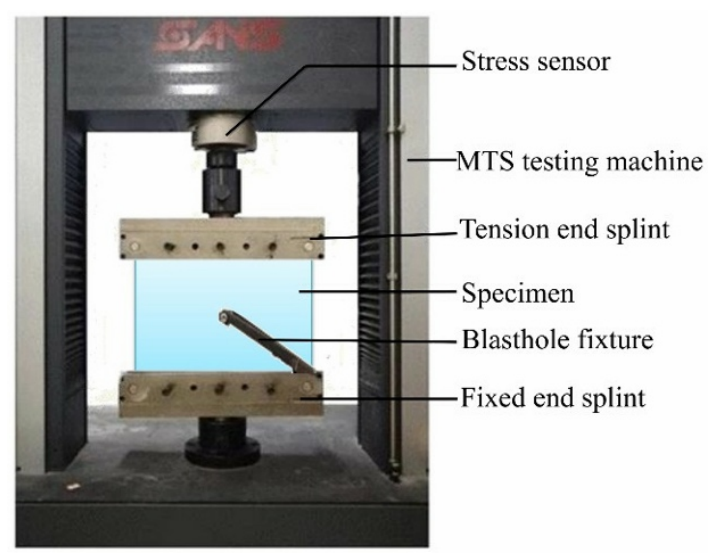

Fig. 2. Dynamic-static combined loading system

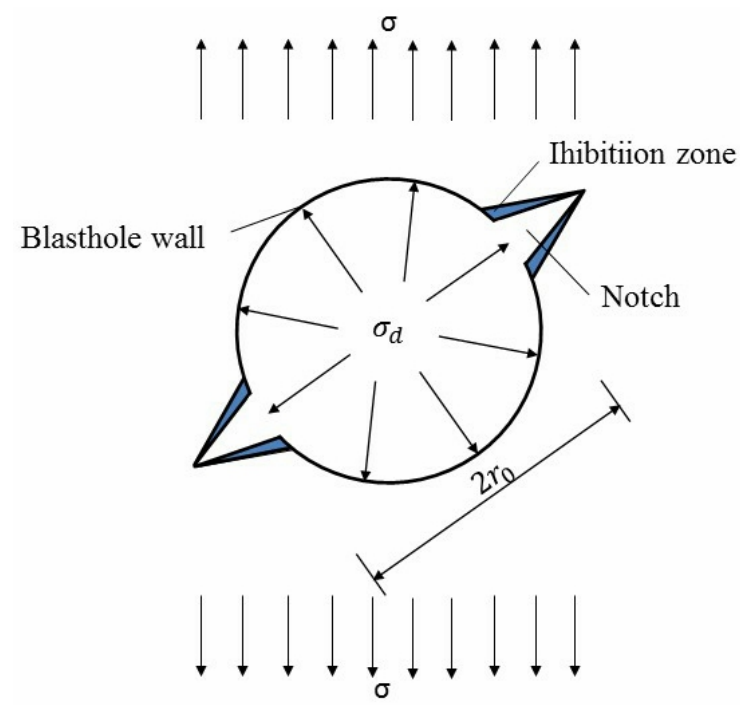

Fig. 3. Mechanical model of the formation phase of the blast-induced main cracks

The mechanical model of the propagation phase of the blast-induced main cracks is shown in Fig. 4. The blasted medium was an infinitely big plate with a blasthole (radius $r_{0}$ ) in the center. The initial uniformly distributed tensile stress $\sigma$ acted in the vertical direction of the plate. The $\beta$ in the figure is the included angle between the directions of the notch and the initial uniformly distributed tensile stress. Under the action of the blasting stress wave, a crack was formed in the notch direction. The blast-induced gas further drove the crack propagation due to the attenuation in the blasting stress.
Assuming that the crack propagation length was $2 a$, to simplify the calculation, the quasi-static pressure caused by the blast-induced gas $\sigma_{\mathrm{d}}$ to the blasthole wall was set equal to the linear load $\sigma_{\mathrm{m}}$.

The action exerted by the initial tensile stress $\sigma$ on the specimen is illustrated in Fig. 4 (b). The stress intensity factor at crack tip can be expressed as follows:

$$
\begin{aligned}
& K_{\mathrm{I}}^{s}=\sigma \sqrt{\pi\left(r_{0}+a\right)} \sin ^{2} \beta \\
& K_{\mathrm{II}}^{s}=\sigma \sqrt{\pi\left(r_{0}+a\right)} \sin \beta \cos \beta
\end{aligned}
$$

where $K_{\mathrm{I}}^{s}$ and $K_{\mathrm{II}}^{s}$ are the respective static stress intensity factors of Modes I and II under the action of the initial tensile stress.

As shown in Fig. 4 (c), under the quasi-static pressure $\sigma_{\mathrm{m}}$ of the blast-induced gas, the stress intensity factor at the crack tip can be obtained according to the stress intensity factor as below:

$$
\begin{aligned}
& K_{\mathrm{I}}^{d}=\sigma_{\mathrm{m}} F \sqrt{\pi\left(r_{0}+a\right)} \\
& K_{\mathrm{II}}^{d}=0
\end{aligned}
$$

where $K_{\mathrm{I}}^{d}$ and $K_{\mathrm{II}}^{d}$ are the respective stress intensity factors of Modes I and II under the action of blast-induced gas; $F$ is the correction coefficient of the stress intensity factor.

According to the superposition principle of combined load in elasticity, the following results can be obtained as follows:

$$
\begin{aligned}
& K_{\mathrm{I}}=K_{\mathrm{I}}^{s}+K_{\mathrm{I}}^{d}=\left(\sigma_{\mathrm{m}} F+\sigma \sin ^{2} \beta\right) \sqrt{\pi\left(r_{0}+a\right)} \\
& K_{\mathrm{II}}=K_{\mathrm{II}}^{s}+K_{\mathrm{II}}^{d}=\sigma \sqrt{\pi\left(r_{0}+a\right)} \sin \beta \cos \beta
\end{aligned}
$$

According to the maximum tensile stress-induced crack initiation criterion, the following expressions can be obtained as follow:

$$
\left(\sigma \sin ^{2} \beta+\sigma_{\mathrm{m}} F\right) \sin \varphi+\sigma \sin \beta \cos \beta(3 \cos \varphi-1)=0
$$

Where $\varphi$ is the crack initiation angle.

When $F=1$ and $\sigma_{\mathrm{m}}=n \sigma$, the above formula can be expressed as follows:

$$
\left(\sin ^{2} \beta+n\right) \sin \varphi+\sin \beta \cos \beta(3 \cos \varphi-1)=0
$$

The relationship between the crack initiation angle $\varphi$ and the tilt angle $\beta$ is shown in Fig. 5. When $0^{\circ} \leq \beta \leq 90^{\circ}, \varphi$ varies within $-70.5^{\circ}-0^{\circ}$. When $\beta$ is fixed, $\varphi$ decreases as $n$ increases, indicating that the relationship between the blastinduced gas and the initial tensile stress exert an influence on the latter.

\subsection{Failure modes of the specimens}

The cracks distribution after the notched blasting is shown in Fig. 6. As shown in Fig. 6 (a). The propagation length of the blast-induced main crack on specimen S1-1 under the sole 
action of blasting stress was $115 \mathrm{~mm}$ without obvious deflection phenomenon. Under the joint action of the initial tensile stress and blasting stress, the blast-induced main crack on specimen S1-2 deflected toward the direction perpendicular to initial tensile stress and ran through the specimen, which propagated up to $153 \mathrm{~mm}$. When the included angle between the notch and the initial tensile stress was $45^{\circ}$, the latter promoted the propagation of the blastinduced main crack, consequently deflecting the main crack along the direction perpendicular to the latter.

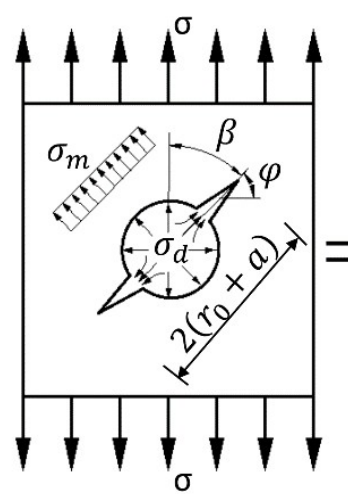

(a)

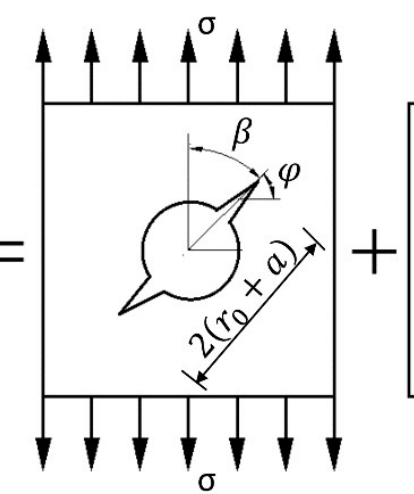

(b)

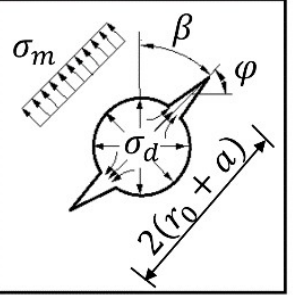

(c)

Fig. 4. Mechanical model of the propagation phase of the blast-induced main cracks

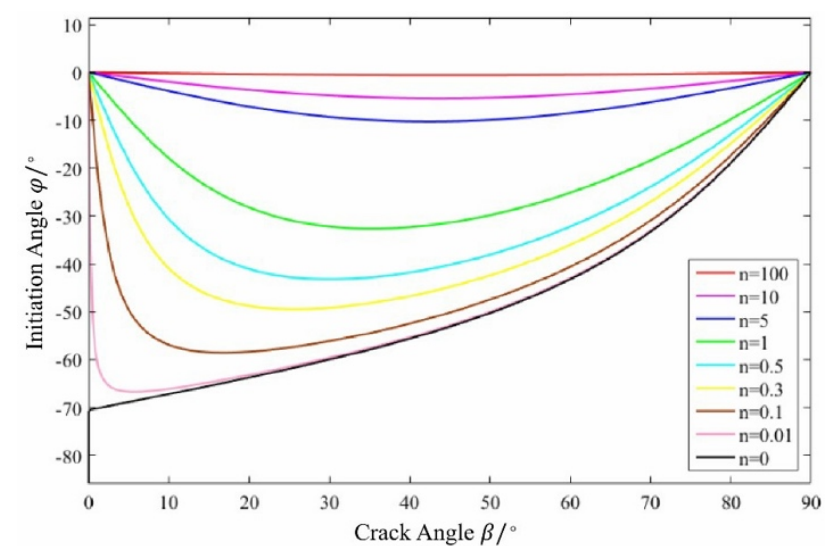

Fig. 5. Relationship between crack initiation angle $\varphi$ and tilt angle $\beta$

As shown in Fig. 6 (b). Under the action of blasting stress, the propagation length of the blast-induced main crack on specimen S2-1 was $55 \mathrm{~mm}$, and only one obvious secondary crack appeared on the horizontal direction at the right side of the blasthole. Nevertheless, under the combined action of the tensile stress and blasting stress, the propagation length of the blast-induced main crack on specimen S2-2 was shorter than that on specimen S2-1 (43 $\mathrm{mm})$. Two long secondary cracks along the horizontal direction appeared at the two sides of the blasthole. The main cracks of both specimens were propagated along a straight line without deflection. The above analysis indicated that when the notch was parallel to the initial tensile stress, the latter would promote the generation of the secondary cracks. Under the effect of blasting stress, the generation of secondary cracks would consume a large quantity of blast energy and reduce the energy applied to the main crack propagation, consequently shortening the propagation length of the main crack.

\subsection{Propagation behavior of blast-induced main cracks}

The dynamic caustic pots of the failure process of specimen S1-1 is shown in Fig. 7. According to the size and motion trail of the caustic spots, the motion velocity and propagation length of the blast-induced main crack can be calculated, and the time-dependent motion law of the main crack was studied. Under the action of blasting stress, the caustic spots of specimen S1-1 moved along a straight line without obvious deflection (Table. 3 and Fig. 7). With the increase in time, the diameter of the caustic spots gradually decreased until the cracking was stopped. For specimen S1-2, the caustic spots experienced deflection in the direction perpendicular to the initial tensile stress when the main crack started propagating. The position of the caustic spots indicates that the motion trail of the caustic spots experienced obvious deflection at $140 \mu \mathrm{s}$. The maximum deflection angle $\left(47^{\circ}\right)$ appeared at $220 \mu$ s, which then moved to the specimen boundary along the direction of the maximum deflection angle. In addition, the entire motion trail of the caustic spots in the S2 group implied that the diameter of the caustic spots gradually decreased until the crack stopped propagating.

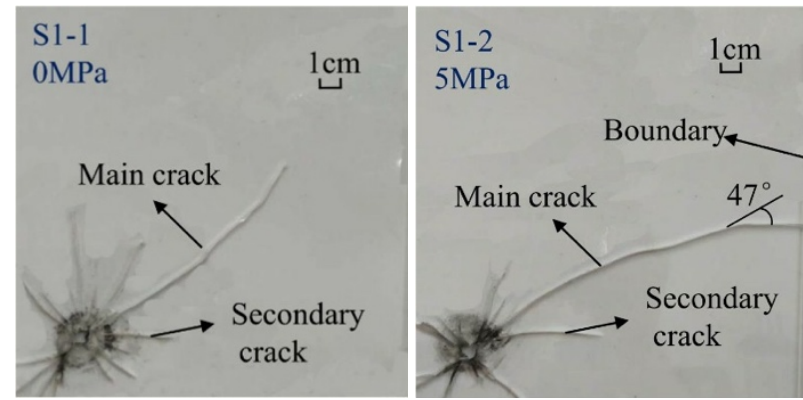

(a) S1 group

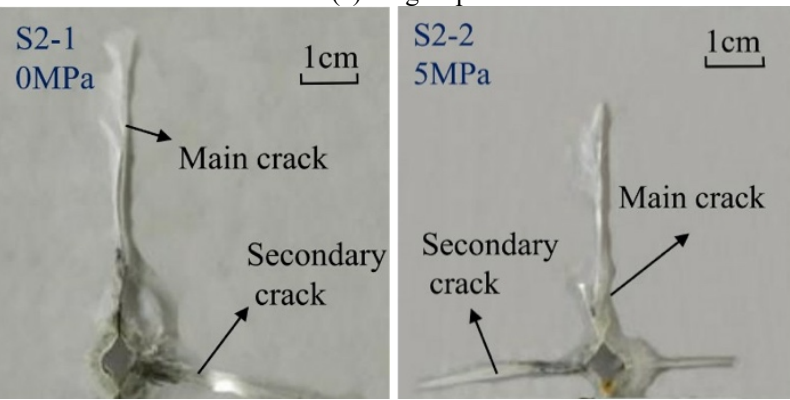

(b) S2 group

Fig. 6. Cracks distributions on the specimens after notched blasting 

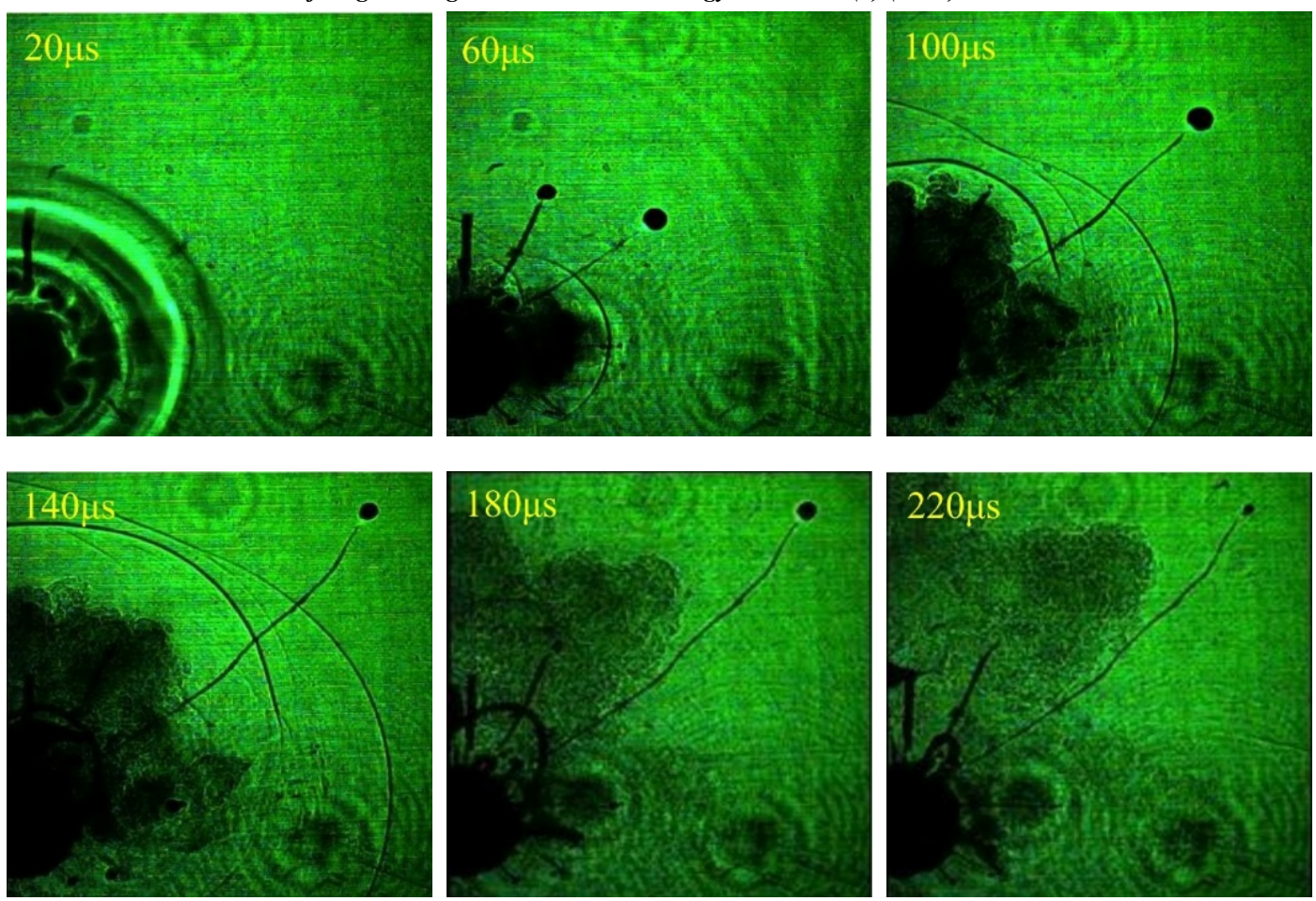

Fig. 7. Dynamic caustic pots during the failure process of specimen S1-1

Table 3. Relation between deflection angle $\left({ }^{\circ}\right)$ and time of specimens in the $\mathrm{S} 1$ group

\begin{tabular}{c|c|c|c|c|c|c}
\hline T (us) & $\mathbf{2 0}$ & $\mathbf{6 0}$ & $\mathbf{1 0 0}$ & $\mathbf{1 4 0}$ & $\mathbf{1 8 0}$ & $\mathbf{2 2 0}$ \\
\hline S1-1 & 2 & 2 & 3 & 1 & -2 & -46 \\
S1-2 & 1 & -5 & -11 & -22 & -36 & -47 \\
\multicolumn{6}{l}{ (Note: the deflection angle is the rincluded angle between the crack propagation direction and the notch at different times; anticlockwise and clockwise }
\end{tabular}

(Note: the deflection angle is the included angle between the
represent the positive and negative direction, respectively)

The time-dependent change curves of the propagation length and velocity of the blast-induced main crack in the S1 group are shown in Figs. 8 and 9. The propagation length of the main crack parallel and perpendicular to the notch direction were defined as $\mathrm{L}_{/ /}$and $\mathrm{L}_{\perp}$, respectively. Similarly, the propagation velocity of the main crack parallel and perpendicular to the notch direction were denoted as $\mathrm{V}_{/ /}$and $\mathrm{V}_{\perp}$, respectively. During the entire propagation process, the L// of specimens S1-1 and S1-2 reached the maximum values at $240 \mu \mathrm{s}$ (144 $\mathrm{mm}$ and $153 \mathrm{~mm}$, respectively). The specimens exhibited minimal difference in terms of $\mathrm{L} / /$ and $\mathrm{V}_{/ /}$, indicating that the initial tensile stress had minor effect on $\mathrm{L}_{/ /}$and $\mathrm{V}_{/ /}$. However, the $\mathrm{L}_{\perp}$ and $\mathrm{V}_{\perp}$ of specimen $\mathrm{S} 1-2$ started to increase at $100 \mu \mathrm{s}$, which can be ascribed to the attenuation of the blasting stress action. Consequently, the initial tensile stress dominated and promoted the $\mathrm{L}_{\perp}$ and $\mathrm{V}_{\perp}$ of specimen $\mathrm{S} 1-2$. The overall $\mathrm{L}_{\perp}$ and $\mathrm{V}_{\perp}$ of specimen $\mathrm{S} 1-1$ were small and are thus excluded from the analysis. The findings imply that when the included angle between the initial tensile stress and notch is $45^{\circ}$, the initial tensile stress exert a minor effect on the propagation of the main crack parallel to the notch direction and an evident one on the propagation perpendicular to the notch direction. Hence, the main crack deflected toward the direction perpendicular to the initial tensile stress.

The time-dependent change curves of the propagation length and velocity of the blast-induced main cracks in the S2 group are shown in Figs. 10 and 11. Fig. 10 shows that before $160 \mu \mathrm{s}$, the main crack propagation on specimens S21 and S2-2 was continuous under the action of blasting shock wave. The propagation lengths of the main cracks of the two specimens were $55 \mathrm{~mm}$ and $43 \mathrm{~mm}$, respectively. On the whole, the propagation velocity of the main crack on specimen S2-1 was higher than that on specimen S2-2 (Fig. 11 ), which verifies the analysis result in section 4.2. When the notch was parallel to the initial tensile stress, the initial tensile stress promoted the generation of the secondary cracks in the horizontal direction of the blasthole, thereby consuming a large quantity of blast energy. As a result, the energy applied to the main crack propagation decreased and the propagation length of the main crack in the notch direction was shortened.

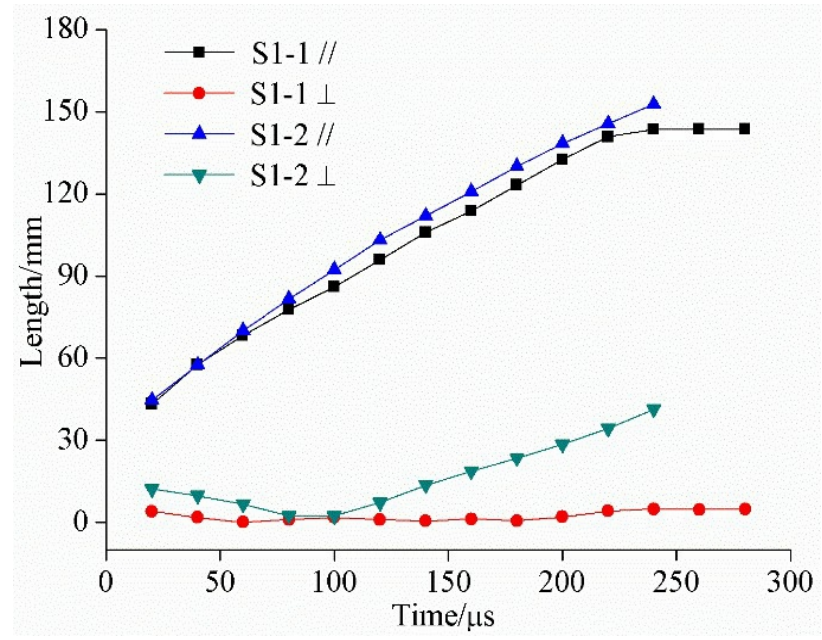

Fig. 8. Propagation length-time curves of the blast-induced main cracks in the $\mathrm{S} 1$ group 


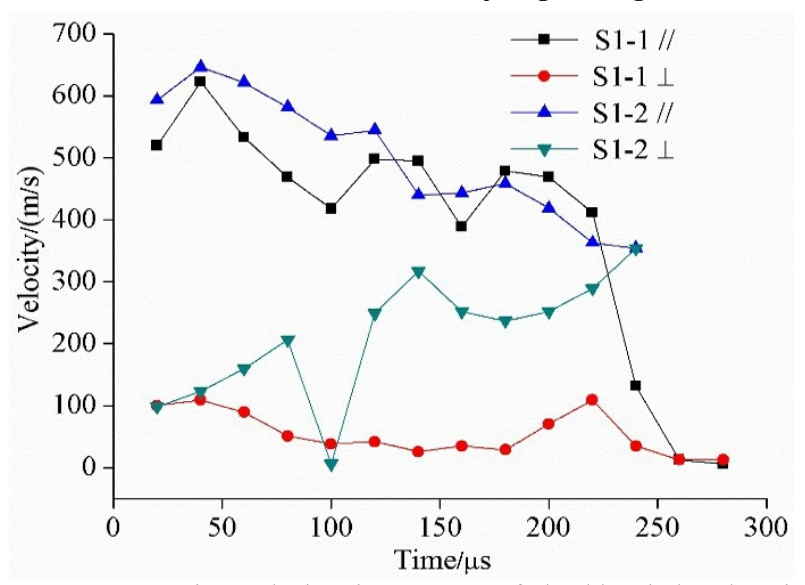

Fig. 9. Propagation velocity-time curves of the blast-induced main cracks in the $\mathrm{S} 1$ group

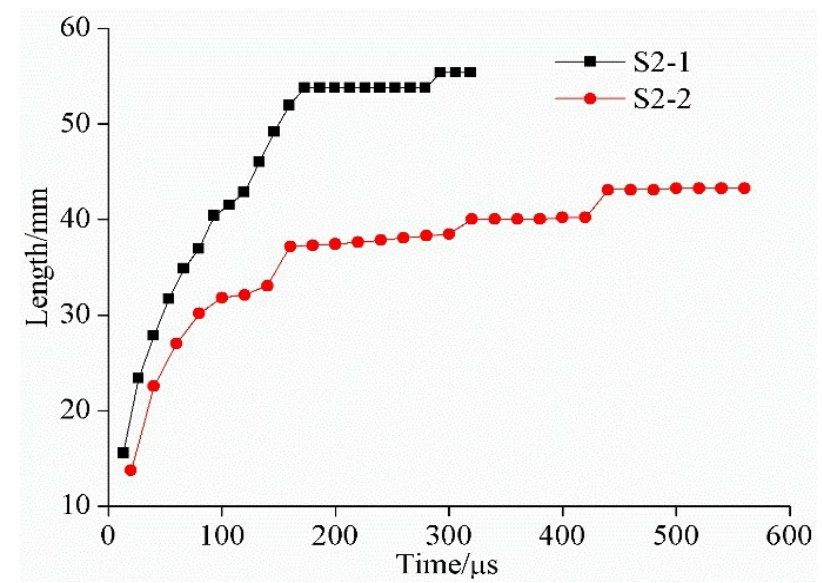

Fig. 10. Propagation length-time curves of the blast-induced main cracks in the $\mathrm{S} 2$ group

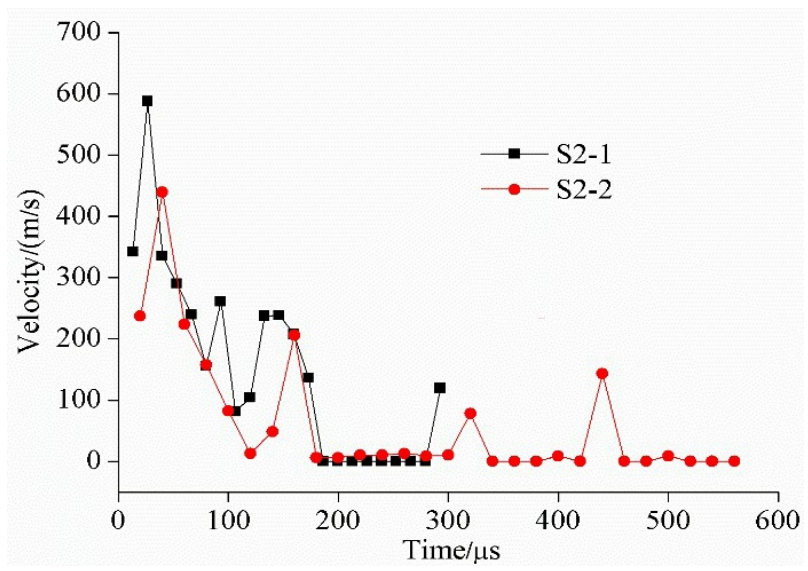

Fig. 11. Propagation velocity-time curves of the blast-induced main crack in the S2 group

\subsection{Analysis of the stress intensity factor}

The time-dependent change curve of the dynamic stress intensity factors $K_{\mathrm{I}}^{d}$ and $K_{\mathrm{II}}^{d}$ of the blast-induced main cracks in the $\mathrm{S} 1$ group is shown in Fig. 12. The $K_{\mathrm{I}}^{d}$ of specimen S1-2 was greater than that of specimen S1-1. The maximum $K_{\mathrm{I}}^{d}$ values of the two specimens were 0.68 $\mathrm{MPa} \cdot \mathrm{m}^{1 / 2}$ and $1.36 \mathrm{MPa} \cdot \mathrm{m}^{1 / 2}$, respectively. Comparing the change curves of the two specimens, the $K_{\mathrm{II}}^{d}$ of specimen S1-1 changed by nearly $0 \mathrm{MPa} \cdot \mathrm{m}^{1 / 2}$, whereas the overall stress intensity factor of specimen S1-2 was large. The above analysis indicated that when the included angle between the notch and the initial tensile stress is $45^{\circ}$, the initial tensile stress increases the stress intensity factor of the main crack and changes the corresponding propagation mode of main crack (Mode I is changed into I-II mixed Mode I-II). In conclusion, the initial tensile stress was the main reason for the deflection of the main crack toward the direction perpendicular to the initial tensile stress.

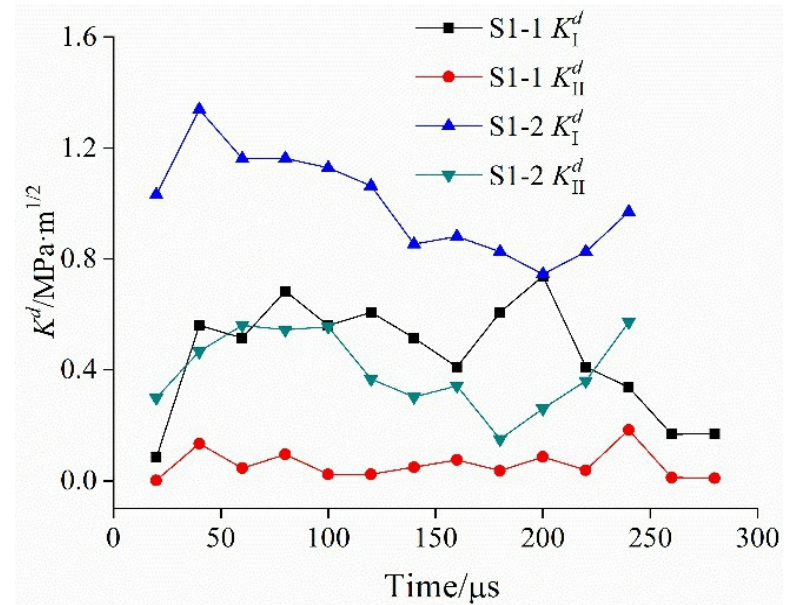

Fig. 12. Stress intensity factor-time curves of the blast-induced main cracks in the $\mathrm{S} 1$ group

The time-dependent change curves of the dynamic stress intensity factor $K_{\mathrm{I}}^{d}$ of the blast-induced main crack in the $\mathrm{S} 2$ group are shown in Fig. 13. The $K_{\mathrm{I}}^{d}$ of specimens S2-1 and S2-2 demonstrated identical change trends with peak values of $1.91 \mathrm{MPa} \cdot \mathrm{m}^{1 / 2}$ and $1.63 \mathrm{MPa} \cdot \mathrm{m}^{1 / 2}$, respectively. It's noteworthy that the $K_{\mathrm{I}}^{d}$ of specimen $\mathrm{S} 2-2$ was greater than that of specimen S2-1 before $160 \mu \mathrm{s}$, after which the difference became minor because many secondary cracks were generated by the initial tensile stress and a large quantity of blast energy was consumed. However, the energy applied to the main crack propagation was small, thereby reducing the stress intensity factor at the main crack tip. These findings indicate that when the notch is parallel to the initial tensile stress, the initial tensile stress reduces the stress intensity factor at the main crack tip.

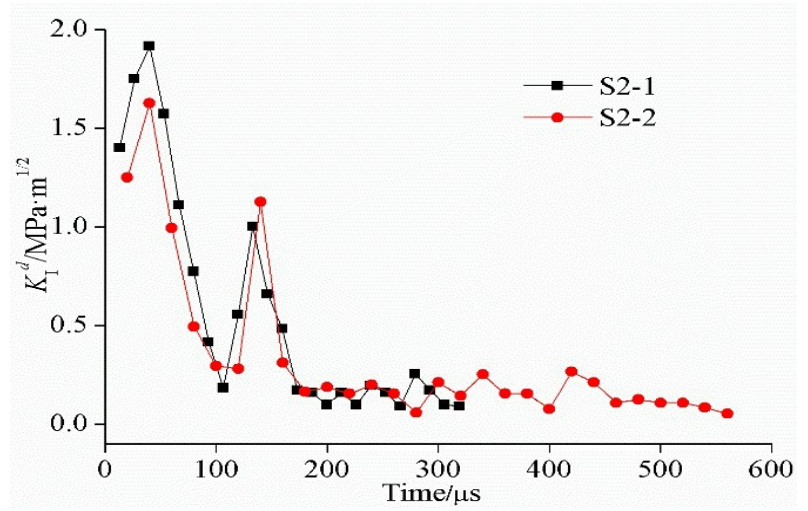

Fig. 13. Stress intensity factor-time curves of the blast-induced main cracks in the $\mathrm{S} 2$ group

\section{Conclusions}

To investigate the blast-induced cracks propagation behavior of notched blasting under the joint action of blast stress and static tensile stress, the deflection laws of the blast-induced main cracks under the action of the latter were theoretically 
summarized in this study. Furthermore, the effects of the initial static tensile stress on the specimen failure modes and propagation behavior characteristics of blast-induced main cracks were studied through the model experiment. The following conclusions were drawn:

(1) The initial static tensile stress changes the stress distribution around the notched blasthole and consequently influences the distribution characteristics of the blastinduced cracks.

(2) When the included angle between the notch and the initial tensile stress is $45^{\circ}$, the initial tensile stress promotes the propagation of blast-induced main cracks parallel and perpendicular to the notch direction, in which the promoting effect on the latter is more remarkable than that on the former. Under the action of the initial tensile stress, the stress intensity factors ( $K_{\mathrm{I}}^{d}$ and $K_{\mathrm{II}}^{d}$ ) of the main cracks increase, the propagation mode changes from Mode I into Modes I-II, and the main crack deflects along the direction perpendicular to the initial tensile stress. The directional blasting effect cannot be achieved under this phenomenon.

(3) When the notch is parallel to the initial tensile stress, the blast-induced main crack presents linear propagation along the notch direction with a significant directional blasting effect. The initial tensile stress promotes the generation of the secondary cracks at the two sides of the blasthole, reduces the stress intensity factor at the main crack tip, and shortens the propagation length of the main crack. The expected blasting effect can be achieved by adding explosive in the relevant engineering practice under this phenomenon.

In summary, the dynamic-static combined loading device and digital laser caustic experimental system were utilized in this study to investigate the dynamic mechanical behavior of blast-induced cracks under the influence of the initial static tensile stress field. The physical quantities of the blast-induced main cracks, such as length, velocity, and stress intensity factor at crack tip, were quantitatively analyzed to provide a basis for the adjustment of the notched blasting parameters under complicated engineering conditions. However, it is impossible to clearly observe the changes caused by the initial tensile stress to the stress around the blasthole. Therefore, further verifications through numerical simulation is essential.

\section{Acknowledgements}

The authors are grateful for the support provided by the National Natural Science Foundation of China (Grant No: 51974316)

This is an Open Access article distributed under the terms of the Creative Commons Attribution License

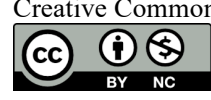

\section{References}

1. Ge, S., Zhong, M. S., Wang, M., Long, Y., Liu, Y., Xu, J. L., "Collapse process and impact effect of viaduct demolition based on centrifugal model". Soil Dynamics and Earthquake Engineering, 115, 2019, pp.246-251.

2. Nesterova, Y. S., "Experience of destressing slotting to prevent gasdynamic events in mechanized carnallite mining". Journal of Mining Science, 53(2), 2017, pp.291-298.

3. Wang, Y. B., "Study of the dynamic fracture effect using slotted cartridge decoupling charge blasting". International Journal of Rock Mechanics and Mining Sciences, 96, 2017, pp.34-46.

4. Lisjak, A., Figi, D., Grasselli, G., "Fracture development around deep underground excavations: Insights from FDEM modelling". Journal of Rock Mechanics and Geotechnical Engineering, 2014.

5. Vazaios, I., Vlachopoulos, N., Diederichs, M. S., "Assessing fracturing mechanisms and evolution of excavation damaged zone of tunnels in interlocked rock masses at high stresses using a finitediscrete element approach". Journal of Rock Mechanics and Geotechnical Engineering, 2019(4).

6. Milner, D., Wesevich, J., Nikodym, L., Nasri, V., Lawver, D., Mould, J., "Improved blast capacity of pre-engineered metal buildings using coupled CFD and FEA modeling". Journal of Loss Prevention in the Process Industries, 56, 2018, pp.486-497.

7. Fourney, W. L., Dally, J. W., Holloway, D. C., "Controlled blasting with ligamented charge holders". International Journal of Rock Mechanics \& Mining Sciences \& Geomechanics Abstracts, 15(3), 1978, pp.121-129.

8. Fourney, W. L., Barker, D. B., Holloway, D. C., "Model studies of explosive well stimulation techniques". International Journal of Rock Mechanics \& Mining Sciences \& Geomechanics Abstracts, 18(2), 1981, pp.113-127.

9. Kim, J. G., Song, J. J., "Abrasive water jet cutting methods for reducing blast-induced ground vibration in tunnel excavation". International Journal of Rock Mechanics and Mining Sciences, 75, 2015, pp.147-158.

10. Stockwell, M., Tadic, D., "Blasthole slotting: Reducing over breakage during coal mine blasting”. Australian Mining Technology Conference: Technology Changing the Mining Business Footprint. CRC Mining, 2010.

11. Liu, C. W., Lu, Y. Y., Xia, B. W., Yu, P., "Directional fracturing by slotting-blasting-caused stress wave form changes". International Journal of Impact Engineering, 129, 2019, pp.141-151.
12. Yang, G. L., Yang, R. S., Huo, C., Pan, C. C., "Research of Influence Factors of Initial Crack with Slotted Charge Blasting". Advanced Materials Research, 143-144, 2010, pp.797-801.

13. Dammyr, O., Nilsen, B., Gollegger, J., "Feasibility of tunnel boring through weakness zones in deep Norwegian subsea tunnels". Tunnelling and Underground Space Technology, 69, 2017, pp.133146.

14. Yang, R. S., Ding, C. X., Li, Y. L., Yang, L. Y., Zhao, Y., "Crack propagation behavior in slit charge blasting under high static stress conditions". International Journal of Rock Mechanics and Mining Sciences, 119, 2019, pp.117-123.

15. Konicek, P., Soucek, K., Stas, L., Singh, R., "Long-hole destress blasting for rock-burst control during deep underground coal mining”. International Journal of Rock Mechanics \& Mining Sciences, 61(2013), 2013, pp.141-153.

16. Drover, C., Villaescusa, E., Onederra, I., "Face destressing blast design for hard rock tunnelling at great depth". Tunnelling and Underground Space Technology, 80, 2018, pp.257-268.

17. Xie, L. X., Lu, W. B., Zhang, Q. B., Jiang, Q., H., Chen, M., Zhao, J., "Analysis of damage mechanisms and optimization of cut blasting design under high in-situ stresses". Tunnelling and Underground Space Technology, 66, 2017, pp.19-33.

18. Reddy, S. K., Sastry, V. R., "Stress Distribution on Blasting Gallery Barrier Pillar due to Goaf Formation During Extraction". Journal of the Institution of Engineers, 97(2), 2015, pp.1-9.

19. Paluszny, A., Zimmerman, R. W., "Modelling of primary fragmentation in block caving mines using a finite-element based fracture mechanics approach". Geomechanics and Geophysics for Geo-Energy and Geo-Resources, 3(2), 2017, pp.121-130.

20. Li, J. P., Feng, C. G., Zhou, C. B., Zheng, Z. Q., "Study of basic parameters on local grooving top-caving with controlled explosion". Chinese Journal of Rock Mechanics and Engineering, 23(4), 2004, pp.650-650.

21. Rossmanith, H. P., Fourney, W. L., "Fracture initiation and stress wave diffraction at cracked interfaces in layered media I. brittle/brittle transition". Rock Mechanics, 14, 1982, pp.209-233.

22. Kutter, H. K., Fairhurst, C., "On the fracture process in blasting". International Journal of Rock Mechanics and Mining Sciences \& Geomechanics Abstracts. Pergamon, 8(3), 1971, pp.181-202. 